\title{
Early identification of patients at high risk of group A streptococcus-associated necrotizing skin and soft tissue infections: a retrospective cohort study
}

\author{
Tomas Urbina', Camille Hua ${ }^{2,3}$, Paul-Louis Woerther ${ }^{3,4,5}$, Armand Mekontso Dessap ${ }^{1,3,6}$, Olivier Chosidow ${ }^{2,3,5}$ and
} Nicolas de Prost ${ }^{1,3,6^{*}}$ (D)

Keywords: Necrotizing soft tissue infection, Group A streptococcus, Toxin, Intravenous immunoglobulins,

Clindamycin

\section{Dear Editor,}

Necrotizing soft tissue infections (NSTIs) are a heterogeneous group of devastating diseases involving a wide variety of microorganisms and affecting different body areas. The need for individualized treatment strategies has been recently put forward in a prospective cohort study of 402 patients in which group A streptococcus (GAS) infections were associated with more frequent septic shock [1]. Early identification of patients with GAS-related NSTIs could prompt initiation of targeted interventions, including clindamycin and intravenous immunoglobulins (IVIg). These drugs might be associated with beneficial antitoxinic properties, but the level of evidence supporting them remains low (clindamycin) or highly controversial (IVIg) [2, 3]. The only randomized clinical trial evaluating the effect of IVIg specifically in patients with NSTI could not demonstrate a benefit on a composite outcome of death and quality-of-life evaluation at 6 months [4]. As previously commented [5], only $15 \%(n=13 / 87)$ of included patients eventually had a microbiologically proven GAS NSTI. This was a major limitation and early identification of patients with a high probability of GASassociated NSTIs would thus be crucial for further studies evaluating similar interventions.

A secondary analysis of a retrospective cohort including 224 patients admitted to our center for NSTI between

\footnotetext{
* Correspondence: nicolas.de-prost@aphp.fr

${ }^{1}$ Service de Réanimation Médicale, Hôpitaux Universitaires Henri Mondor, Assistance Publique - Hôpitaux de Paris (AP-HP), Créteil, France

${ }^{3}$ Université Paris-Est Créteil Val de Marne (UPEC), Créteil, France

Full list of author information is available at the end of the article
}

2006 and 2017 was conducted [6]. In accordance with the most recent guidelines, only patients with surgically confirmed NSTI were included (i.e., macroscopic appearance of tissues during operation as swollen, dull gray with a thin, brownish exudate with or without necrosis). Admission characteristics and microbiological documentation based on surgical samples, blood cultures, or subcutaneous puncture were recorded. We compared patients with a documented GAS infection to other patients regarding admission characteristics. A multivariable logistic regression model was used to identify admission characteristics associated with a subsequent GAS documentation.

Among 224 patients, 60 (27\%) had a GAS infection, which was monomicrobial in 39 (17\%) cases. Overall, $134(59.8 \%)$ patients were admitted to the intensive care unit during their stay, of whom 113 during the first $24 \mathrm{~h}$. Ninety-one (41\%) patients presented with shock (i.e., required vasopressors), and 89 (40\%) required mechanical ventilation. Sixty days after admission, $51(23 \%)$ patients had died, including 10 (17\%) with GAS, and $41(25 \%)$ with non-GAS infections ( $p=0.255$, Mann-Whitney test). Admission characteristics associated with GAS infections by univariable analysis were non-steroidal antiinflammatory drug treatment before admission and leukocytosis as a continuous variable. Those inversely associated with GAS infections were immunodeficiency, the nosocomial onset of infection, and an abdominoperineal location (Table 1). After multivariable analysis, only immunodeficiency (adjusted odds ratio $(\mathrm{aOR})=0.29$ [0.10-0.74], $p=0.015)$ and an abdominoperineal location $(\mathrm{aOR}=0.06[0.00-0.30], p=0.007)$ remained associated 


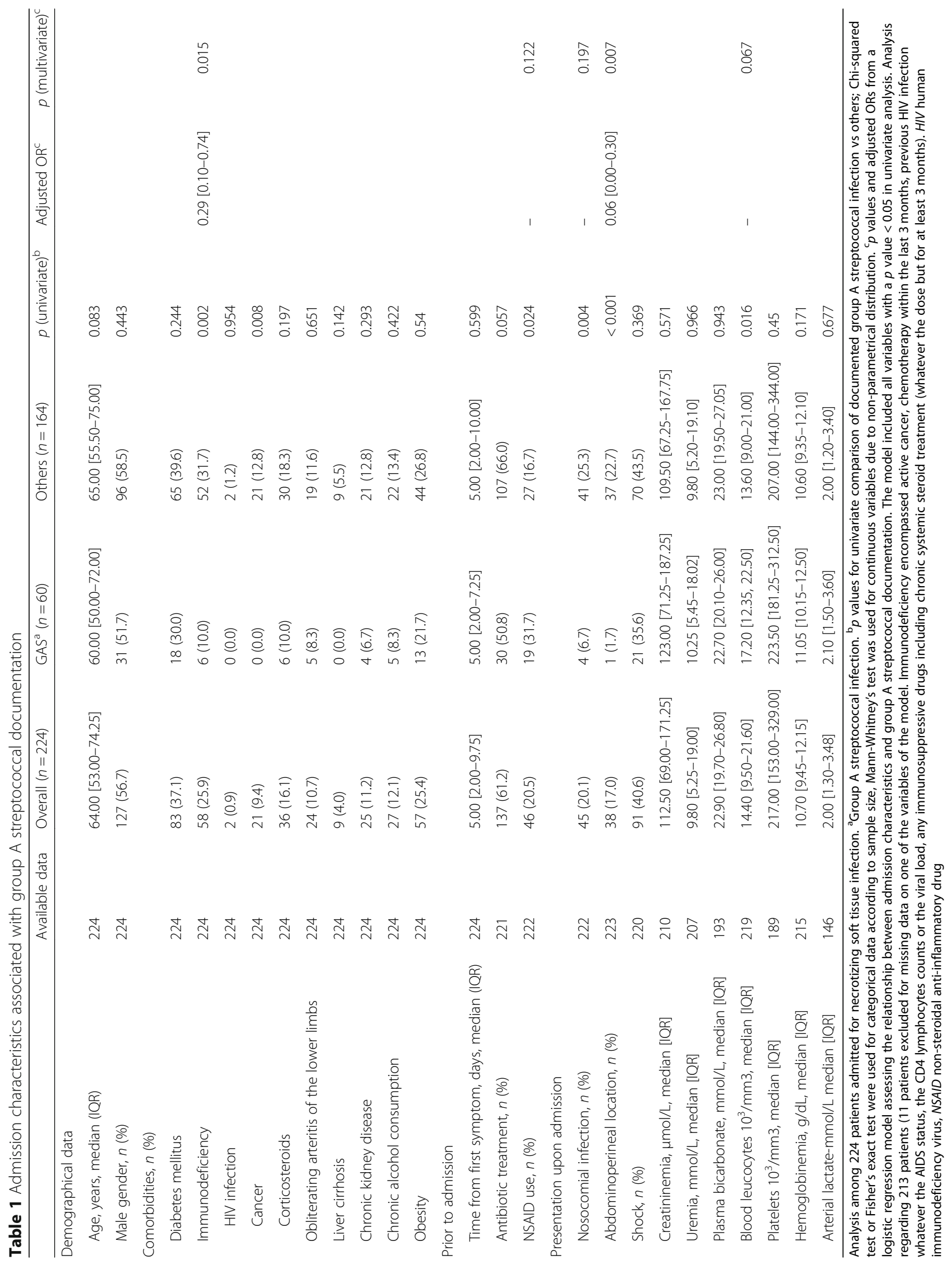


with the absence of GAS infection (Table 1). A sensitivity analysis using "monomicrobial GAS NSTI" as the dependent variable yielded similar results, except for younger age that remained in the model after adjustment (data not shown). Immunodeficiency $(n=58)$ and an abdominoperineal location $(n=38)$ had respective positive predictive values for the absence of a GAS infection (both mono- or polymicrobial) of 90\% [79-96] and 97\% [86-100] (Fig. 1).

In conclusion, we retrospectively identified two simple and available upon admission clinical predictors of GAS documentation among a large cohort of surgically proven NSTIs. Our results show that NSTI patients with pre-existing immunodeficiency or an abdominal infection have a low probability of GAS infection and might thus not be suitable for inclusion in a trial assessing the effect of GAS-specific interventions. Such findings need to be assessed in a validation cohort in order to reinforce their generalizability. Improving identification upon admission of a subgroup of patients with a higher prevalence of GAS infection might help design future prospective trials aimed at assessing personalized treatment strategies [2].

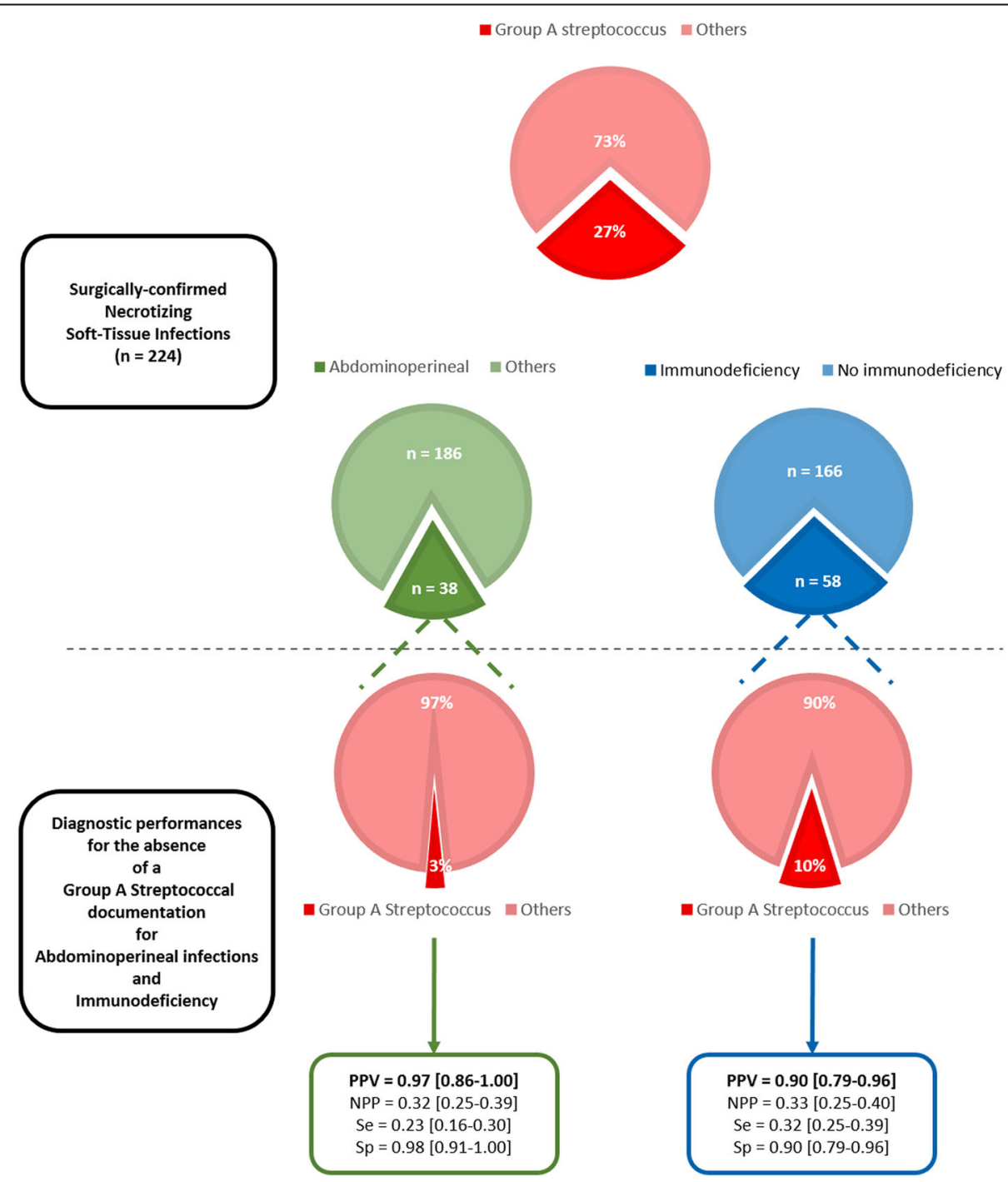

Fig. 1 Diagnostic performances of abdominoperineal location and immunodeficiency for predicting absence of group A streptococcal documentation. The three top pie charts represent the proportions of group A streptococcal documentation, abdominoperineal infections and immunodeficiency in the whole 224-patient population of surgically confirmed necrotizing soft tissue infections. The two bottom pie charts represent the proportion of group A streptococcal documentation in the subgroup of patients with abdominoperineal infections (bottom left chart) or in immunocompromised patients (bottom right chart). Diagnostic performances of an abdominoperineal location of infection and of immunodeficiency for predicting the absence of group A streptococcal documentation were calculated using a contingency table approach. Immunodeficiency encompassed active cancer, chemotherapy within the last 3 months, previous HIV infection whatever the AIDS status, the CD4 lymphocytes counts or the viral load, any immunosuppressive drugs including chronic systemic steroid treatment (whatever the dose but for at least 3 months). PPV, positive predictive value; NPP, negative predictive value; Se, sensitivity; Sp, specificity 


\section{Abbreviations}

GAS: Group A streptococcus; IVIG: Intravenous immunoglobulins; NSTI: Necrotizing soft tissue infection; OR: Odds ratio; PPV: Positive predictive value; NPP: Negative predictive value; Se: Sensitivity; Sp: Specificity

\section{Acknowledgements}

The members of the Henri Mondor Hospital Necrotizing Fasciitis Group are Romain BOSC, Cécile CHAMPY, Olivier CHOSIDOW, Nicolas de PROST, Nicola DE ANGELIS, Jean-Winoc DECOUSSER, Camille GOMART, Jean-Michel GRACIES, Barbara HERSANT, Camille HUA, Raphaël LEPEULE, Alain LUCIANI, Lionel NAKAD, Alain RAHMOUNI†, Emilie SBIDIAN, Françoise TOMBERLI, Tomas URBINA, and Paul-Louis WOERTHER.

\section{Authors' contributions}

All authors were involved in the study conception and design and conducted the study on behalf of the Henri Mondor Hospital Necrotizing Fasciitis Group. TU and NdP collected the data, performed statistical analyses, and wrote the original draft. All authors were involved in interpreting the data and reviewing the final manuscript. All authors read and approved the final manuscript.

\section{Funding}

This work did not receive any funding.

\section{Availability of data and materials}

The dataset used during the current study is available from the corresponding author upon reasonable request.

\section{Ethics approval and consent to participate}

The study was approved by the Comité de Protection des Personnes Ile-deFrance V on March 8, 2018 (reference \#16165). Patients received information during hospital stay that data abstracted from their medical charts could be used for research purposes.

\section{Consent for publication}

Not applicable.

\section{Competing interests}

PLW declares having received lecture fees and conference invitations from MSD.

All other authors declare no competing interest for this work.

\section{Author details}

'Service de Réanimation Médicale, Hôpitaux Universitaires Henri Mondor, Assistance Publique - Hôpitaux de Paris (AP-HP), Créteil, France. '2Service de Dermatologie, Hôpitaux Universitaires Henri Mondor, Assistance Publique Hôpitaux de Paris (AP-HP), Créteil, France. ${ }^{3}$ Université Paris-Est Créteil Val de Marne (UPEC), Créteil, France. ${ }^{4}$ Laboratoire de Bactériologie-Hygiène, Hôpitaux Universitaires Henri Mondor, Assistance Publique - Hôpitaux de Paris (AP-HP), Créteil, France. 'Équipe EA 7380 Dynamyc, Unité de Formation et de Recherche (UFR) de Médecine - site Créteil, Université Paris-Est Créteil Val-de-Marne, Créteil, France. ${ }^{6}$ Groupe de Recherche Clinique CARMAS, Université Paris Est-Créteil, Créteil, France.

Received: 27 November 2019 Accepted: 16 December 2019

Published online: 21 December 2019

\section{References}

1. INFECT study group, Madsen MB, Skrede S, Perner A, Arnell P, Nekludov M, et al. Patient's characteristics and outcomes in necrotising soft-tissue infections: results from a Scandinavian, multicentre, prospective cohort study. Intensive Care Med. 2019;45(9):1241-51.

2. Darenberg J, Ihendyane N, Sjölin J, Aufwerber E, Haidl S, Follin P, et al Intravenous immunoglobulin $\mathrm{G}$ therapy in streptococcal toxic shock syndrome: a European randomized, double-blind, placebo-controlled trial. Clin Infect Dis. 2003;37(3):333-40.

3. Carapetis JR, Jacoby P, Carville K, Ang S-JJ, Curtis N, Andrews R. Effectiveness of clindamycin and intravenous immunoglobulin, and risk of disease in contacts, in invasive group a streptococcal infections. Clin Infect Dis Off Publ Infect Dis Soc Am. 2014;59(3):358-65.
4. Madsen MB, Hjortrup PB, Hansen MB, Lange T, Norrby-Teglund A, Hyldegaard $\mathrm{O}$, et al. Immunoglobulin $\mathrm{G}$ for patients with necrotising soft tissue infection (INSTINCT): a randomised, blinded, placebo-controlled trial. Intensive Care Med. 2017:43(11):1585-93.

5. de Prost N, Lipman J, Mimoz O. Therapeutic targets in necrotizing soft tissue infections. Intensive Care Med. 2017:43(11):1717-9.

6. Urbina T, Hua C, Sbidian E, Bosc R, Tomberli F, Lepeule R, et al. Impact of a multidisciplinary care bundle for necrotizing skin and soft tissue infections: a retrospective cohort study. Ann Intensive Care. 2019;9(1):123.

\section{Publisher's Note}

Springer Nature remains neutral with regard to jurisdictional claims in published maps and institutional affiliations.

\section{Ready to submit your research? Choose BMC and benefit from:}

- fast, convenient online submission

- thorough peer review by experienced researchers in your field

- rapid publication on acceptance

- support for research data, including large and complex data types

- gold Open Access which fosters wider collaboration and increased citations

- maximum visibility for your research: over $100 \mathrm{M}$ website views per year

At $\mathrm{BMC}$, research is always in progress.

Learn more biomedcentral.com/submissions 